\title{
Percepções do ser adulto sobre o evento da deficiência física: um estudo fenomenológico
}

\author{
Perceptions of adults about the physical \\ disability event: a phenomenological study
}

FisiSenectus. Unochapecó Ano 1, n. 1 - Jan./Jun. 2013 p. $35-42$

\section{Daniela Regina Sposito Dias Oliva}

Fisioterapeuta. Especialista em Fisioterapia em Neurologia (PUC/PR). Discente do Programa de Mestrado em Envelhecimento Humano/PPGEH na Universidade de Passo Fundo (UPF).

\section{Marilene Rodrigues Portella}

Enfermeira. Doutora em Enfermagem pela Universidade Federal de Santa Catarina (UFSC). Docente do Programa de Mestrado em Envelhecimento Humano/PPGEH na Universidade de Passo Fundo. Líder do Grupo de pesquisas Vivencer CNPq/UPF

\section{Resumo}

Introdução: a deficiência física é um fenômeno que acomete indivíduos em todas as faixas etárias, porém cabe lembrar que embora envelhecimento e deficiência não sejam sinônimos, a população em geral está a envelhecer, com um risco associado de somatória de deficiências. Conhecer as percepções do ser adulto sobre o evento da deficiência física se torna um desafio a ser enfrentado, e cabe ao fisioterapeuta apreender melhor essa dimensão de seres que vivenciam o impacto de uma lesão ou doença. Objetivo: compreender as percepções de indivíduos adultos com deficiência física adquirida sobre o ser deficiente e o processo de viver e envelhecer, sob o prisma da fenomenologia. Método: participaram quatro pessoas com deficiência física adquirida há mais de dois anos, com idade superior a 36 anos. Este estudo fundamenta-se na Fenomenologia, em especial nos apontamentos de Maurice Merleau-Ponty, cuja ênfase é dada à experiência corporal e à consciência corporal do mundo sensível. Para as entrevistas realizadas a domicílio, utilizou-se de um guia norteador, e para análise dos dados foi utilizado os passos de Giorgi. Resultados: compreenderam três essências acerca do evento desencadeador da deficiência: a) Mobilização acerca das vivências pessoais, b) o fato, a notícia e os seus desdobramentos, c) a dependência... quando o corpo habita o mundo pela mão do outro. Conclusão: o método fenomenológico ancorado no pensamento de Merleau-Ponty possibilitou a compreensão da deficiência por meio das percepções do ser adulto sobre o evento da deficiência física. Enquanto fisioterapeutas, é preciso conhecer e explorar como o ser deficiente se sente com esse corpo, conhecendo as significações que ele atribui ao corpo e, por meio dele, ao mundo em que vivemos. Concluímos esse estudo apresentando indivíduos com deficiência física como sujeitos-seres e não somente como pessoas de corpos deficientes.

\section{Palavras-chave}

Pessoas com deficiência. Gerontologia. Experiência de vida.

\section{Fisiß̌enectus}




\begin{abstract}
Introduction: disability is a phenomenon that affects individuals in all age groups, but it should be remembered that although aging and disability are not synonymous, the general population is aging, with an associated risk of additional disabilities. Knowing the perceptions of being an adult about the event of disability becomes a challenge to be faced, and it is for the physical therapist apprehend this dimension of human beings who experience the impact of an injury or illness. Objective: To understand the perceptions of adults with physical disabilities acquired about be a person with disability and the process of living and aging from the perspective of phenomenology. Method: four individuals with physical disabilities acquired for more than two years. over the age of 36 years. This study is based on phenomenology, especially in the notes of Maurice Merleau-Ponty. Whose emphasis is on corporal experience and corporal conscience of the sensible world. For the household interviews was used for guiding a guide. For data analysis was used in the steps of Giorgi. Results: three essences understood about the triggering event of disability: a) Mobilization about personal experiences, b) the fact, the story and its consequences, c) dependence... When the body inhabits the world by the hand of another. Conclusion: the phenomenological method grounded in the thought of Merleau-Ponty was possible the understanding of disability through the perceptions of being adult about the event of disability. As physiotherapists is necessary to know and explore how it feels to be disabled with that body, knowing the meaning that he assign your body and through him the world. Conclude this study by presenting individuals with physical disabilities as subjects-whole persons, not only as people of disabled bodies.
\end{abstract}

\title{
Keywords
}

Disabled persons. Gerontology. Life Change Events.

\section{Introdução}

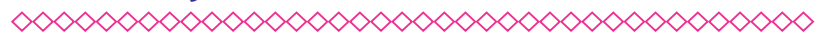

0 assunto deficiência é um campo sólido de debates pouco conhecido no Brasil. O conceito de deficiência varia conforme a instituição ou fonte de dados, independente dessas serem públicas ou privadas. A deficiência pode ser definida no contexto biológico, como a perda ou anormalidade da função de uma estrutura, órgão ou sistema, decorrente de qualquer causa, representando distúrbios que podem ser de natureza anatômica, fisiológica ou psicológica ${ }^{1}$, podendo ser temporária ou permanente ${ }^{2}$. A Declaração sobre os direitos das pessoas com deficiência, a qual foi promulgada por meio do Decreto n. 6949, de 25 de agosto de 20093, traz grandes contribuições em termos conceituais, políticos, sociais, enfim, todo um arcabouço necessário na tentativa de qualificar a vida das pessoas com deficiência. Trata-se de um documento atual, construído com a participação das pessoas com deficiência e que atualmente serve como referência para decisões de políticas públicas para as pessoas com deficiência.

Conjugamos com Resende e Neri ${ }^{4}$, que apontam que a deficiência pode ser socialmente defi- nida como o produto do descompasso entre as condições do indivíduo afetado por uma limitação funcional, as suas expectativas quanto à execução das atividades básicas e instrumentais de vida diária, as demandas ambientais nessa direção e a escassez ou a inadequação de condições instrumentais e sociais que Ihe permitam funcionar adequadamente, mantendo a autonomia e a autoestima.

Indivíduos que nasceram ou que adquiriam alguma deficiência física antes da velhice podem atingir a idade de envelhecer, desde que tenham podido contar com bons cuidados à saúde ${ }^{5,6}$, e, embora envelhecimento e deficiência não sejam sinônimos, a população está a envelhecer com um risco associado de níveis crescentes de deficiência ${ }^{6}$. Sem dúvida, os desafios do envelhecimento normal interagirão com suas limitações físicas e exigirão mais deles e de seu entorno, para que vivam e se desenvolvam da melhor maneira possível ${ }^{7}$.

Ao desenvolver esse estudo sobre percepções de pessoas adultas com deficiência física adquirida sobre o processo de viver e envelhecer com deficiência, focaliza-se um campo inexplorado no Brasil e pouco explicitado na literatura internacional ${ }^{4}$. 0 
olhar fenomenológico busca compreender o ser humano como um todo situado no mundo ${ }^{8}$. Assim, ao buscar outros caminhos para a compreensão do ser humano, essa pesquisa buscará na fenomenologia um suporte teórico.

Nesta perspectiva, a escolha recaiu na abordagem fenomenológica, ancorada em Maurice Merleau-Ponty, pelo fato de conjugar com esse filósofo o entendimento do ser como único, corpo, mente, como sujeito encarnado (concreto que tem corpo próprio, corpo vivo, e se expressa por intermédio dele, assim como sente o seu corpo); e ainda a compreensão de que a pessoa, com uma deficiência ou não, é uma consciência imersa a um corpo que a liga inexoravelmente ao mundo, ${ }^{9,10}$.

A interação com pessoas com deficiência permite-nos saber mais sobre as possibilidades da existência humana e compreender as especificidades perceptuais daqueles que não dispõem de todas as funções do corpo. É preciso acrescentar ao rol de procedimentos de fisioterapeutas (e demais profissionais da saúde), além do foco biológico e técnico, o olhar existencial ao indivíduo enquanto ser.

0 ponto de partida para essa compreensão é estar atento às formas próprias da pessoa com deficiência física explorar e perceber o que a cerca. Neste sentido, o estudo objetivou conhecer e descrever as percepções de indivíduos adultos, frente ao processo de viver e envelhecer com deficiência física adquirida, sob o prisma da fenomenologia.

\section{O caminho para conhecer o ser}

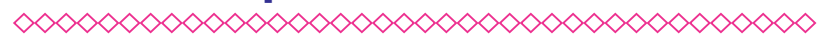

Trata-se de uma pesquisa com abordagem qualitativa de cunho fenomenológico. Para a coleta de dados, adultos aceitaram participar da pesquisa, aos quais foram garantidos a integridade e o sigilo pessoal das entrevistas, utilizando de Termo de Consentimento Livre e Esclarecido, que segue as diretrizes da Resolução CNS n. 196/96, em projeto aprovado pelo Comitê de Ética em Pesquisa da Universidade de Passo Fundo, Parecer $\mathrm{n}$. 137/2011.
Os participantes abaixo descritos são os que aceitaram fazer parte do estudo, e receberam os seguintes pseudônimos:

Luz, uma mulher de 36 anos, paraplégica após lesão medular torácica em acidente automobilístico há 18 anos, que ocasionou a morte de seu único filho, de dois anos.

Rocha, um homem de 40 anos, paraplégico após lesão medular torácica e politraumatismo em acidente de motocicleta indo à madeireira na qual trabalhava. Acidente ocorreu em novembro de 2009.

Aprendiz, um homem de 54 anos, paraparético após lesão traumática em cauda equina durante o dia de trabalho, em julho de 2004.

Atleta, um homem de 48 anos, parético em decorrência da Síndrome de Guillain-Barré, cujos primeiros sintomas aconteceram há 29 anos.

Para coleta, utilizou-se a entrevista fenomenológica, cujas indagações foram orientadas por entrevista aberta e norteada pelo diálogo pesquisadora-pesquisados, com intuito de favorecer a livre expressão dos sujeitos e estimular a abordagem da temática em estudo.

A fenomenologia é um estudo das essências ${ }^{8,9}$, como, por exemplo, a essência da percepção e da consciência, pois a compreensão de sujeito-mundo só pode acontecer a partir da sua facticidade, que está relacionada às vivências de cada sujeito ${ }^{8,11,13}$.

As entrevistas foram realizadas nas residências dos entrevistados, em uma cidade de Santa Catarina, entre os meses de abril e julho de 2011. As falas foram gravadas em meio magnético, meio digital e transcritas na íntegra de acordo com as exigências metodológicas. A organização e a compreensão das informações foram realizadas por meio dos quatro passos do método fenomenológico propostos por Giorgi ${ }^{12}$, acrescido de mais um passo proposto por Comiotto $^{11}$, com o intuito de descrever e perceber cada pessoa dentro de sua singularidade. São eles: primeiro passo: o sentido do todo; segundo passo: as unidades de significado; terceiro passo: transformação das expressões dos participantes em expressões psicossensíveis; quarto passo: síntese das estruturas de significado ${ }^{12}$; e quinto passo: dimensões fenomenológicas ${ }^{11}$. 


\section{A percepção do evento desencadeador da deficiência}

$\infty \times \infty \times \infty \times \infty \times \infty \times \infty \times \infty \times \infty \times \infty \times \infty \times \infty \times \infty \times \infty$

Os participantes da pesquisa, no momento da entrevista, ao se pronunciar sobre o evento desencadeador da deficiência, mesclam-se nos fatos e nos problemas nas mais diversas direções de pensamento, muito pouco distintas nos seus contornos próprios, como as pinturas superpostas num velho quadro, cujas diferentes camadas exigem o máximo cuidado de um técnico para poderem ser separadas de uma maneira que talvez possa ainda motivar as pesquisas em torno deste tema.

Perceber é tornar algo presente a si com a ajuda do corpo, tendo a coisa sempre seu lugar em um horizonte de mundo e consistindo a decifração em colocar cada detalhe nos horizontes que Ihe convenha. Mas tais fórmulas são enigmas a menos que as aproximemos dos desenvolvimentos concretos que elas resumem. ${ }^{9}$ (p. 104).

O fenômeno da deficiência mereceu ser mostrado em toda sua conjuntura, transmitindo o evento desencadeador sem obstruir o caminho, não poupando palavras, para podermos agora, mediante do fato narrado, descobrir-lhe o verdadeiro sentido de viver e envelhecer com deficiência.

\section{a) Mobilização acerca das vivências pessoais}

0 indivíduo com deficiência, por vezes, tem a existência mobilizada por um episódio ou elemento de seu passado (no caso, a doença ou o acidente). Essa essência brota em função de relatos do passado, em que o corpo atual é fadado a carregar: toda recordação, ou qualquer elemento que faça referência a ela, como no caso dos participantes com deficiência física, reabre esse passado, torna-o presente a quem o viveu e obriga o indivíduo a retomá-lo a partir de sua atualidade, como se confere.

A gente tinha a vida muito boa, a vida nossa era muito boa, todo mundo trabalhava [...] todo mundo empregado, casa própria, e eu fiquei doente, [...] praticamente deu um baque na família. [...] antes eu dançava valsa, chote, vanerão!!! Gostava muito de dançar, ganhei concurso de dança [...] Então, eu tive uma época com coisa muito gostosa [...] As meninas me chamavam de bundundinho do Bairro FF, pois eu tinha umas belas de umas coxas, bumbum, e tinha um cabelão e ia jogar futebol, Nossa Senhora! A meninada ia à loucura!!! E de repente fica metade, menos da metade! [...] Nessa época, antes de ficar doente, eu jogava futsal e jogava futebol de campo, de três irmãos que jogavam naquela época lá, todos diziam que eu jogava melhor, jogava muito, jogava em duas ou três equipes de campo [...] talvez se não tivesse acontecido essas coisas comigo de repente teria sido um bom jogador sabe? (Atleta).

O Atleta, rememorando sua trajetória, vê o sonho desfalecendo com o advento do agravo. Para abordar o evento da deficiência, antes de tudo é necessário mobilizar as vivências pessoais, mostrar que aquele corpo foi apreciado e elogiado. Merleau-Ponty considera que "[...] todo recalque é a passagem da existência em primeira pessoa a um tipo de escolástica dessa existência, que vive para uma experiência antiga, ou antes, para a recordação de tê-la tido." ${ }^{\prime 9}$

Diferentemente de Atleta, Rocha, que tinha vida sofrida de madeireiro, mobiliza as vivências pessoais centrado na família, nas recordações do relacionamento com o pai, apresentando a mãe, trazendo presente e passado, com o destaque do distanciamento do pai que perdura mesmo depois do acidente.

Eu e a H. [esposa] começamos umas cinco vezes do nada, de começar só com o colchão pra nós dormirmos e aí fomos indo. Graças a Deus, Deus nunca deixou nós passarmos fome, nunca faltou o que comer, saúde nós sempre tivemos. [...] Era acostumado o dia todo trabalhar e levantar cedo [...] Eu com meu pai nunca deu certo. O meu pai, pra ele tanto fez como tanto faz. Desde 1990 eu sai de casa, fui trabalhar com outras pessoas, por causa que o sistema dele não combinava com o meu [...] Bom, a mãe... Coitada! Ela tem Alzheimer, acho que isso aí de tanto ficar calada, a mãe não podia falar nada, porque o pai é um ignorante. Aí um dia nós tivemos um briga lá e eu falei pra mãe: 'eu vou sair pro mundo! Porque senão uma hora dá uma besteira, fica pior né?!' Eu sei que pai é pai, a gente tem que ter consideração [...], mas sabe, ele passou um ano bem certinho antes de vir na minha 
casa, depois da lesão, aí no começo do ano ele veio, depois até hoje não veio mais [...] Minha esposa e as pessoas de fora me ajudaram mais que a minha própria família. (Rocha).

0 pronunciamento de Aprendiz mobiliza as qualidades em torno de si, irradiando certo modo de existência, comparando suas atitudes de antes da lesão e do momento presente.

Antes eu tinha uma maneira, as minhas atitudes, os afazeres eram diferentes; hoje até pra conversar eu tenho mais calma. Eu era bem explosivo antes [...] Por exemplo, antes eu achava que era só com os outros que acontecia as coisas, a gente não analisa, de fora, o que é passar por isso. (Aprendiz).

Para Merleau-Ponty, a relação entre o sujeito da percepção e o mundo percebido é de expressão, ela se estabelece a partir do interior do próprio mundo. A experiência do evento ou da realidade não é a realidade para um sentido apenas, ela é a experiência da plena coexistência do sujeito com o fenômeno, o momento em que sob todos os aspectos ele estaria em seu máximo de articulação9. É preciso mobilizar as vivências pessoais para poder avançar na descrição do evento.

Luz, por sua vez, ao mobilizar-se acerca das vivências anteriores, anuncia que:

A deficiência física em si é muito complicada, desde o momento que ocorre o acidente contigo e você fica paraplégica. A minha perda assim em si foi muito maior, pois não perdi só o meu corpo, uma parte do meu corpo no acidente, perdi meu filho que é a coisa mais importante pra uma mãe, né? (Luz).

Merleau Ponty ${ }^{9}$ defende ser a visão fenomenológica do homem, do mundo e seus acontecimentos, aberta aos diversos fatores existenciais. A compreensão de algo deve ser entendida pelos vários aspectos em que se apresenta. Nesse sentido, Luz atribuiu sentido à deficiência pelas experiências do vivido, pelas perdas anunciadas. Para compreendermos a deficiência, é necessário também conhecer o fato nas suas projeções.

\section{b) O fato, a notícia e os seus desdobramentos}

A recordação do evento não se limita a citação do fato, antes de tudo configura-se como um momento de apreciar uma realidade vivenciada em todos os seus sentidos. Ou seja, "[...] um certo tipo de simbiose, uma certa maneira que o exterior tem do nos invadir, uma certa maneira que nós temos de acolhê-lo, e aqui a recordação apenas resgata a armação da percepção da qual ela nasceu." ${ }^{\prime 9}$ (p. 366).

Para Merleau-Ponty, o mundo não é apenas aquilo que penso, mas também o irrefletido ${ }^{10}$. Nesse sentido, não é possível admitir uma experiência sempre subjugada ao crivo do juízo, mas é preciso admitir a experiência original e Aprendiz ao relatar o fato o faz em todos os seus sentidos:

\begin{abstract}
A lesão, o acidente meu, um caminhão me prensou. Um colega meu tava trabalhando no caminhão. Ele trabalhava em outro setor, na outra parte, e ele bateu arranque no caminhão, e estava com a marcha engatada, e eu estava na frente, de costas para o caminhão. Eu tava nas bancada mexendo, e que passou assim do meu lado, eu vi que abriu a porta do caminhão, eu vi que funcionou o caminhão [...] eu vi assim que o caminhão já tava quase me prensando naquela bancada que eu tava trabalhando. Quando eu vi que não tinha onde escapar eu tentei me jogar pra cima da bancada, mas não deu tempo. Ele me pegou bem certo como eu pulei, ele me pegou bem na lombar. (Aprendiz).
\end{abstract}

No curso da narrativa, Aprendiz aciona seus sentidos, direciona a mão espalmada sobre o corpo, na região lombar, e prossegue seu relato:

Aí eu só senti aquela prensada entre a bancada, aquele estralo. Eu senti um calor que desceu nas minhas pernas, ai ele conseguiu desligar. Quando ele desligou o caminhão, o caminhão perdeu a pressão e voltou. Eu tentei jogar o peso nas pernas, mas não tinha mais pernas. Eu desci com tudo, veio ferramenta, veio as peças, veio tudo por cima, e eu caí, caí rolando. E eu já senti aquela dor. Aí vi que ele desligou o caminhão e correu lá pra me pegar. Quando ele chegou, eu não tava aguentando mais a dor, consegui falar pra ele: 'não mexe, não me mexe, que se foi a minha coluna.' Aí ele quis me pegar de novo e eu disse: 'não bota a mão em mim, deixa aí!!' Eu sabia, porque nós fazia aqueles treinamentos. (Aprendiz). 
Aprendiz prossegue em sua narrativa dando ênfase no relato: "já escutei de longe assim: 'não mexe nele que eu já chamei os bombeiros'". Sua voz neste momento se torna um grito bradado, e, numa trajetória entre passado e presente, entre momentos de exaltação e silêncio, entre expressões reveladoras de admiração e espanto, prossegue.

Aí deu sorte!!! Senão eu tava até hoje numa cadeira de rodas! [...] Chegou o socorro, bem rápido, não levou cinco minutos eles estavam ali. 0 bombeiro começou a falar e disse que deu bem no meio da lombar. A dor era insuportável. Ele disse: mexe as pernas. E eu disse: não consigo mexer as pernas. (Aprendiz).

De forma semelhante, ao narrar o evento, Rocha se vale da forma como Ihe noticiaram o fato.

Fiquei internado por 66 dias. Me dei conta que tinha tido uma lesão medular no segundo, terceiro dia, quando cheguei lá no hospital na primeira noite eu já não sentia as pernas, daí tava ali... Aí eu falava para a enfermeira: 'eu quero virar de lado, que eu não consigo dormir'. E ela: 'não pode! não pode! tem que ficar assim, nós não podemos mexer contigo'. Só que ela também não falou né, aíno outro dia de tarde entrou o médico, daí eu falei pra ele, digo: 'doutor eu queria me virar, porque eu não consigo dormir assim'. Aí ele foi e falou pra mim: 'Oh, não dá pra você se mexer, você tá com a coluna quebrada, a tua lesão não pode e nós não podemos fazer cirurgia por isso e por isso.' [...] Eu nunca tinha conversado com ninguém. Foi tudo assim... Bem dizer, fui aprendendo por mim mesmo. (Rocha).

Percebemos o mundo com o nosso corpo $^{9,14}$, e a revelação de Rocha demonstra que a percepção da deficiência acontece à medida que o seu corpo dava o sinal, ao mesmo tempo em que a notícia da lesão se torna uma vivência diária, bem como as sucessivas manifestações de "não" acontecem. Não pode isso, não pode aquilo, não pode... não pode...

Na experiência da deficiência, "[...] a consciência abre mão de definir o mundo para deixá-lo falar. São as próprias coisas, do fundo do seu silêncio, que se deseja conduzir à expressão."10 (p. 16).

Eu tinha dor por causa da lesão [...] eu tentava me torcer, mas não tinha como, aí foi horrivel, eu passei dor. Com colete cervical eu fiquei 90 dias, até cicatrizar a vértebra. (Rocha).
Então quando isso aconteceu comigo, eu pensei: 'minha vida zerou!' Zerou porque eu não pude fazer mais nada, tocar mais nada da minha vida, em toda parte: o esporte parou; o estudo parou; o trabalho fechou, em vez de entrar, saia; ai eu tava aqui, fiquei três meses aqui em Concórdia mais três meses pra quatro em Chapecó e depois de lá fui pra Florianópolis, fiquei mais seis meses, então quer dizer o quê? Eu fiquei todo esse período sem saber de nada dentro de um hospital. Então você não era nada [...] Só que daí você não andava, tu corria antes mas não corria mais, nem fazer mais as tuas necessidades tu não fazia mais sozinho. (Atleta).

Eu fiquei trinta dias mais ou menos sem dormir. Eu não fechava o olho pra dormir, dia e noite. Não sei se era preocupação ou se era o meu corpo que tava acostumado de um jeito e ficou só na cama, só deitado. Quase trinta dias sem dormir. (Aprendiz).

Para a ciência, o corpo é reduzido a um objeto que tem sua existência no modelo mecânico, no qual as partes são exteriores entre si e em que as únicas relações possíveis são de pura exterioridade, compreendidas mecanicamente ${ }^{14}$.

Para Merleau-Ponty, o corpo é parte do mundo e "é o movimento do ser no mundo"9 (p. 117), por meio de seu corpo é capaz de perceber e de projetar-se no mundo sensível que o rodeia. Quando a "vida zerou", ela o faz porque o corpo assim se manifesta, mostra o relacionamento com o mundo de um corpo antes desenvolto, agora inerte e frágil. 0 corpo fenomenal ${ }^{9}$ (outro nome dado por Merleau-Ponty ao corpo próprio) não é um elemento negativo e impreciso no processo de apreensão da realidade. Tampouco ele é um elemento a ser transcendido ou superado em vista de uma substância ideal. Nesse sentido, o corpo fenomenal é a própria essência humana se mobilizando em direção ao mundo, a rede dos atos intencionais que animam a sua percepção ${ }^{9}$.

\section{c) A dependência... quando o corpo habita o mundo pela mão do outro}

Merleau-Ponty refere que o corpo é o veículo de ser no mundo, e ter um corpo é para um ser vivo juntar-se a um meio definido ${ }^{9}$. 0 homem tem consciência do seu mundo por meio do seu corpo, assim, o seu mundo fica vulnerável à medida que 
seu corpo se fragiliza, que se torna dependente, como se confere na fala do Atleta.

No hospital tinha a enfermeira que dava banho e a vergonha? Só que quando você está ali numa cama de hospital você não pensa nisso, você não se manda, você recebe medicamento, recebe alimentação. (Atleta).

O Atleta é essencialmente ser no mundo com o seu corpo, um ser que se revela nas suas forças, no movimento de ir e vir, na plenitude de sua coordenação motora; assim, hospitalizado sente-se só e desamparado, principalmente na condição de dependência. A itinerância nos espaços hospitalares desvela um corpo esvaindo-se do mundo.

Então fechou pro mundo, saia de um hospital e ia pra outro hospital, e ali e em vez de decidir de meIhorar tu só piorava, ficava mais pra trás. Antes, tu tinha força nas pernas, tu não tinha mais, tu sentava não podia sentar mais, sentava na cadeira tinha que amarrar a cadeira, pra tomar banho de sol tinha que ser na cadeira e ainda não tinha coordenação motora nenhuma. Tua mente ligada, tua sensibilidade ligada, só tu vendo você, teu corpo indo embora sabe, cada dia você vendo os músculos da tua perna, tua musculatura sumindo. (Atleta).

Para Merleau-Ponty, o corpo é forma de expressão, pleno de intencionalidade e poder de significação ${ }^{9}$. Assim, o corpo estacionário amedronta por desvelar o poder-não-estar-mais-presente, por representar um fechamento às inúmeras possibilidades de vir-a-ser enquanto corpo arte. 0 corpo que submete no espaço hospitalar é um corpo guiado pela vontade do outro. O hospital é espaço de temor pela continua possibilidade de não-ser-mais, no qual a resignação é presente como compreensão da dependência.

Você era uma pessoa nova, cheio de esperança, com uma vontade enorme de ser alguém na vida e não poder nem ser você, sabe? Você não poder nem sair de um lugar pro outro. E você não é mais, você não se governa mais, você não se manda, tem que aceitar o que fizerem pra ti, queria um copo de água, tá com sede, a gente tava com fome, de comer alguma coisa, você tem que esperar alguém te dar. Eu tinha vontade de gritar, às vezes não conseguia nem gritar, tinha que me segurar! (Atleta).
0 acidente, ah! Depender dos outros, de um copo d'água, comida, tem que dar tudo na boca, é difícil. [...] a escara durou um ano e três meses, demorou para a ferida cicatrizar, ali foi a fase mais difícil, porque tem que fazer curativo quatro, cinco vezes por dia. Banho, era só pano, que não dava pra virar, movimentar, porque não tinha como se movimentar. (Rocha).

E eu era dependente, simplesmente dependente de tudo, pra fazer tudo. Transferência, tudo! [...] Você não é mais do mesmo jeito, porque você usa sonda, você fica totalmente dependente. [...] Então, eu dependia das pessoas. (Aprendiz).

Para Merleau-Ponty, consciência e corpo são inseparáveis. 0 corpo não é apenas um objeto físico, e sim "aparência" de uma interioridade ${ }^{15}$. Intrinsecamente ligado a esta interioridade, o corpo se transforma em um instrumento com 0 qual o homem habita o mundo e a ele pertence ${ }^{9,15}$. $\mathrm{Na}$ condição de dependência, o corpo só habita o mundo pela mão do outro, pela vontade do outro. 0 outro que é o familiar, o enfermeiro, o cuidador, o fisioterapeuta.

\section{Reflexões finais}

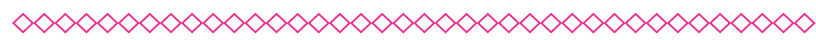

0 método fenomenológico ancorado no pensamento de Merleau-Ponty possibilitou a compreensão da deficiência por meio das percepções do ser adulto sobre o evento da deficiência física. Nossas experiências constituem a fonte de todo o conhecimento, sendo adquirido no próprio mundo, um mundo que existe ao nosso redor e que só passa a existir efetivamente para nós quando Ihe atribuímos um sentido. Enquanto fisioterapeutas, que trabalham com pessoas com deficiência, especialmente a física, é preciso conhecer e explorar como o ser deficiente se sente com esse corpo, que não só se sente pertencente ao mundo, como também frequenta-o, e de forma compreensível atribui-Ihe uma significação. 0 mundo é inesgotável, pois o conhecimento que podemos ter dele é em perspectiva, havendo várias possibilidades ou ângulos de apreendê-lo. Assim, o sentido que atribuímos à deficiência física é dependente de nossas vivências. 
O profissional da saúde, em especial o fisioterapeuta, precisa apreender essa dimensão do sujeito compreendendo o fenômeno como um todo. É necessário desprender-se de concepções pautadas somente no conhecimento biológico e fragmentado. Vale a pena compreender o indivíduo também sob o prisma do ser existencial que se mostra para o cuidado de suas mãos. Após a conclusão desse estudo, apresentam-se indivíduos com deficiência física como sujeitos-seres, e não e tão somente como pessoas de corpos deficientes.

\section{Referências}

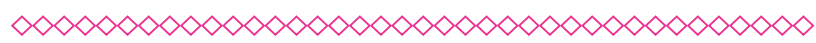

1. Diniz D. O que é deficiência. São Paulo: Brasiliense, 2007.

2. Amiralian MLT, Pinto EB, Ghirardi MIG, Lichtig I, Masini EFS e Pasqualin L. Conceituando deficiência. Rev. Saúde Pública. 2000;34(1): 97-103.

3. Brasil. Convenção Internacional sobre os Direitos das Pessoas com Deficiência e seu Protocolo Facultativo, assinados em Nova York, em 30 de março de 2007. DECRETO No 6.949, DE 25 DE AGOSTO DE 2009.

4. Resende MC, Neri AL. Atitudes de adultos com deficiência física frente ao idoso, à velhice pessoal e a pessoas com deficiência física. Estudos de Psicologia. 2005; 22(2):123-131.

5. Harrison TC, Umberson D, Lin LC, Cheng HR. Timing of impairment and health-promoting lifestyles in women with disabilities. Qual Health Res. 2010;20(6):816-29.

6. Harrison, Tc; Stuifbergen A. A hermeneutic phenomenological analysis of aging with a childhood onset disability. Health Care Women Int. 2005;26:731.
7. Medeiros M, Diniz D. Envelhecimento e deficiência. In: Camarano, AA, organizadora. Os Novos Idosos Brasileiros: Muito Além dos 60 ? Rio de Janeiro, IPEA; 2004:107-120.

8. Benincá CRS, Gomes WB. Apoio psicológico à enfermagem diante da morte: estudo fenomenológico [Tese de Doutorado]. Universidade Federal do Rio Grande do Sul, Porto Alegre; 2002.

9. Merleau-Ponty M. (2006). Fenomenologia da percepção. São Paulo: Martins Fontes. p. 104.

10. Merleau-Ponty M. O visível e o invisível. São Paulo: Perspectiva, 2000.

11. Comiotto MS. Adultos médios: sentimentos e trajetória de vida: estudo fenomenológico e proposta de auto-educação [Tese de Doutorado]. Faculdade de Educação, Universidade Federal do Rio Grande do Sul; 1992.

12. Giorgi A. The descriptive phenomenological method in psychology: a modified Husserlian approach. Pittsburgh, Pennsylvania: Duquesne University Press, 2010.

13. Moreira V. O método fenomenológico de Merleau-Ponty como ferramenta crítica na pesquisa em psicopatologia. Psicologia: Reflexão e Crítica, 2004; 17 (3): 447-456.

14. Cardim L N. A ambiguidade na Fenomenologia da percepção de Maurice Merleau-Ponty [Tese de Doutorado]. Universidade de São Paulo, São Paulo; 2007.

15. Menezes TMO, Lopes RLM, Azevedo RF. A pessoa idosa e o corpo: uma transformação inevitável. Rev. Eletr. Enf. 2009;11(3):598-604. 